\title{
Ronchi test visibility as a function of illumination source size and duty cycle of the Ronchi ruling
}

\section{Visibilidad en la prueba de Ronchi en función del tamaño de la fuente de iluminación y el factor de llenado de la rejilla}

\author{
Javier Álvarez Jiménez ${ }^{(\mathrm{E})}$, Alberto Cordero Dávila $\left.{ }^{*}, \mathrm{~A}\right)$ \\ Benemérita Universidad Autónoma de Puebla, Puebla, México. \\ ${ }^{(*)}$ Email: acordero@fcfm.buap.mx \\ A: miembro de AMO / AMO member \\ Recibido / Received: 07/09/2012. Revisado / Revised: 14/01/2013. Aceptado / Accepted: 16/01/2013. \\ DOI: http://dx.doi.org/10.7149/OPA.46.1.29
}

\begin{abstract}
:
By using an exact ray tracing, we have numerically calculated the ronchigram visibility, $V$, as a function of linear source size, $L$, and duty cycle, $c$, of the Ronchi ruling. We simulated the cases for which extended source is or not from behind Ronchi ruling. We found $V$ decreases if $L$ grows and we have reproduced the common case in which $V$ is substantially improved if extended source is from behind Ronchi ruling. In this last case visibility diminishes when duty cycle is increased.
\end{abstract}

Key words: Ronchi Test, Visibility, Duty Cycle.

\section{RESUMEN:}

Usando trazo exacto de rayos, hemos calculado la visibilidad, $V$, de ronchigramas en función del tamaño de la fuente lineal, $L$, y el factor de llenado, $c$, de la rejilla de Ronchi. Simulamos los casos para los cuales la fuente extendida está o no está detrás de la rejilla de Ronchi. Encontramos que $V$ decrece si $L$ aumenta y logramos reproducir el común caso en el que $V$ mejora sustancialmente si la fuente extendida está detrás de la rejilla de Ronchi. En este último caso la visibilidad disminuye cuando el factor de llenado se incrementa.

Palabras clave: Prueba de Ronchi, Visibilidad, Factor de Llenado.

\section{REFERENCIAS Y ENLACES / REFERENCES AND LINKS}

[1]. A. Cornejo, "Ronchi test", pp 321-365 in Optical Shop Testing, 3 ${ }^{\text {rd }}$ Edition. D. Malacara, Edt. Wiley, New York (1992).

[2]. V. Ronchi, "Le frange di combinazioni nello studio delle superficie e dei sistemi ottici", Riv. Ottica Mecc. Precis. 2, 9 (1923).

[3]. V. Ronchi "Due nuovi metodi per lo studio delle superficie e dei sistemi ottici", Ann. Sc. Norm. Super Pisa., 15 (1923).

[4]. D. Malacara, “Geometrical Ronchi test of aspherical mirrors", Appl. Opt. 4, 1371-1374 (1965). DOI

[5]. G. Toraldo di Francia, "Geometrical and interferential aspects of the Ronchi test”, in Optical Image Evaluation, Natl. Bur. Stand. (U.S.) Circ. No. 256, U.S. GPO, Washington, D.C. (1954).

[6]. J. Braat, A. J. E. M. Janssen, "Improved Ronchi test with extended source", J. Opt. Soc. Am. A 16, 131140 (1999). DOI

[7]. A. Cordero, E. Luna, S. Vázquez, M. Percino, "Ronchi test with a square grid", Appl. Opt. 37, 672-675 (1998). DOI

E Estudiante de la Licenciatura en Física, Benemérita Universidad Autónoma de Puebla (México). 
[8]. A. Cordero, A. Cornejo, O. Cardona, "Ronchi and Hartmann tests with the same mathematical theory", Appl. Opt. 31, 2370-2376 (1992). DOI

[9] J. R. Katún-Montiel, Estimación del Error en una Superficie Óptica mediante Simulación de Ronchigramas con una Rejilla Cosenoidal, Splines Cúbicos y Algoritmos Genéticos, Masters Thesis, Benemérita Universidad Autónoma de Puebla, México (2011)

\section{Introduction}

In Ronchi test [1-5], increasing the source size $(L)$, decreases the visibility (V) (Fig. 1(a)). However, if the Ronchi ruling is placed between extended source and the mirror (Fig. 2), then the visibility improves (Fig. 1(b)). On the other side, it is known that ronchigram characteristics depend on ruling structure $[6,7]$.

We used geometric optics to simulate ronchigrams with a linear extended source, placed after or before Ronchi ruling. This last was defined by its period and duty cycle $(c)$. For every ronchigram, we calculated the visibility and completed the calculations of $\mathrm{V}$ as a function of $L$ and $c$.

In next section 2 we shall describe the developed computer program. In section 3 we discuss the obtained results and finally we shall show our conclusions.

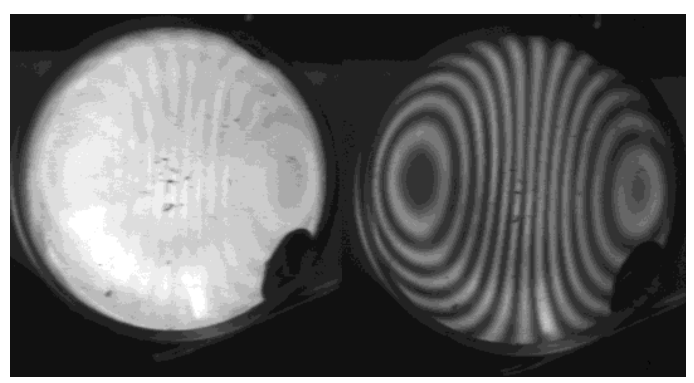

Fig. 1: Ronchigrams with: a) extended light source and b) extended source and a Ronchi ruling from behind.
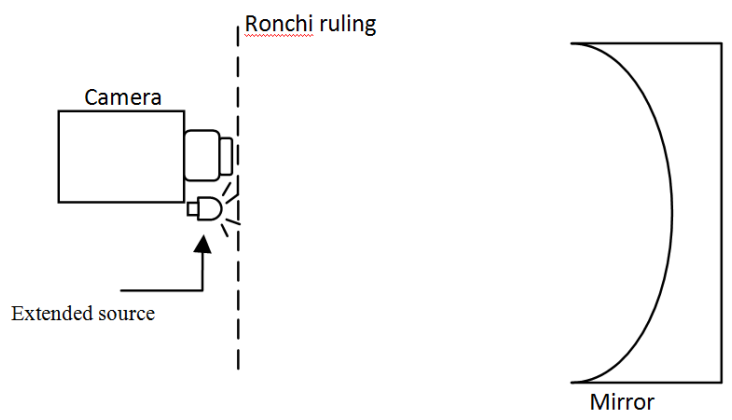

Fig. 2: Description of the experimental setup.

\section{Simulation algorithm}

We started from a computer program used to simulate ronchigrams for concave mirrors with point source at any position [8] and with a cosinusoidal ruling [9]. A linear source (oriented transversally to ruling lines) was simulated by placing 50 point sources per every period of Ronchi ruling.

For every point of the linear source ronchigram irradiance was computed along a set of points homogeneously distributed along $X$ axis on the mirror. Next, irradiances of those ronchigrams, were summed to obtain irradiance, $I(x)$, of an extended source ronchigram.

We used maximum, $I_{\max }$, and minimum, $I_{\text {min }}$, irradiances to compute visibility, $V$, of each extended source ronchigram, given by:

$$
\mathrm{V}=\frac{I_{\text {max }}-I_{\text {min }}}{I_{\text {max }}+I_{\text {min }}} .
$$

From previous calculations we obtained $\mathrm{V}=\mathrm{V}(L)$.

It was added to the computer program the option of including the ruling immediately after the source, for this we placed only point sources in transparent area of the ruling. This Ronchi ruling region had the same period and orientation that the region used for observation.

For the description of illumination Ronchi ruling we will use the duty cycle variable:

$$
c=\frac{b}{d^{\prime}}
$$

where $b$ and $d$ correspond to transparent width and period of the Ronchi ruling respectively, see Fig. 3. Observation ruling still was cosinusoidal.

With described computer program we are able to compute the next functional dependence $\mathrm{V}=\mathrm{V}(L, c)$ with domain $0 \leq c \leq 1$ and $0 \leq L \leq 16 d$, where $d$ is Ronchi ruling period. In next section we shall analyze obtained general results. 


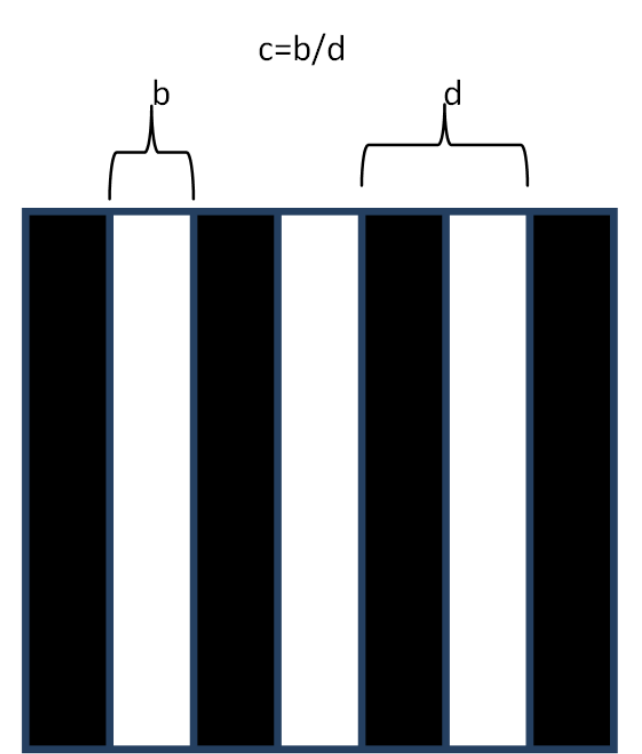

Fig. 3: Description of the duty cycle, $c$, of a Ronchi ruling.

\section{Obtained results}

In Fig. 4(a) the plots of visibility vs. linear source size are shown for three Ronchi ruling periods (corresponding to frequencies 25, 50 and 100 lines per inch). We can see that visibility, V, falls faster when the ruling period decreases. Nevertheless, if we use ruling period as measure unity for source size, $L$, then all visibility plots match, as you can see in Fig. 4(b).

In Fig. 4(b) we can see that $V=1$ if $L=0$ (punctual source). However as $L$ starts growing, visibility falls quickly and comes to cero when $L$ is equal to one ruling period, $d$. For higher values of $L$ visibility increases a little, achieving a maximum before $L$ is equal to one and a half ruling period, and falling to cero when $L$ is equal to two ruling periods. The same behavior is seen for higher $L$, being the ceros for integer values of $d$, with the difference that maxima have a smaller value as $L$ grows.

A graph of $V$ as a function of $L$ is shown in Fig. 4(c), for the ruling placed between the source and the mirror. It can be seen that visibility improves substantially, which reproduces experimental results (see Fig. 1). This is, visibility decreases when $L$ increases, and $V$ tends to a constant value of 0.63 , with small variations.

Figure 5 shows a graph of $\mathrm{V}=\mathrm{V}(L, C)$ with a
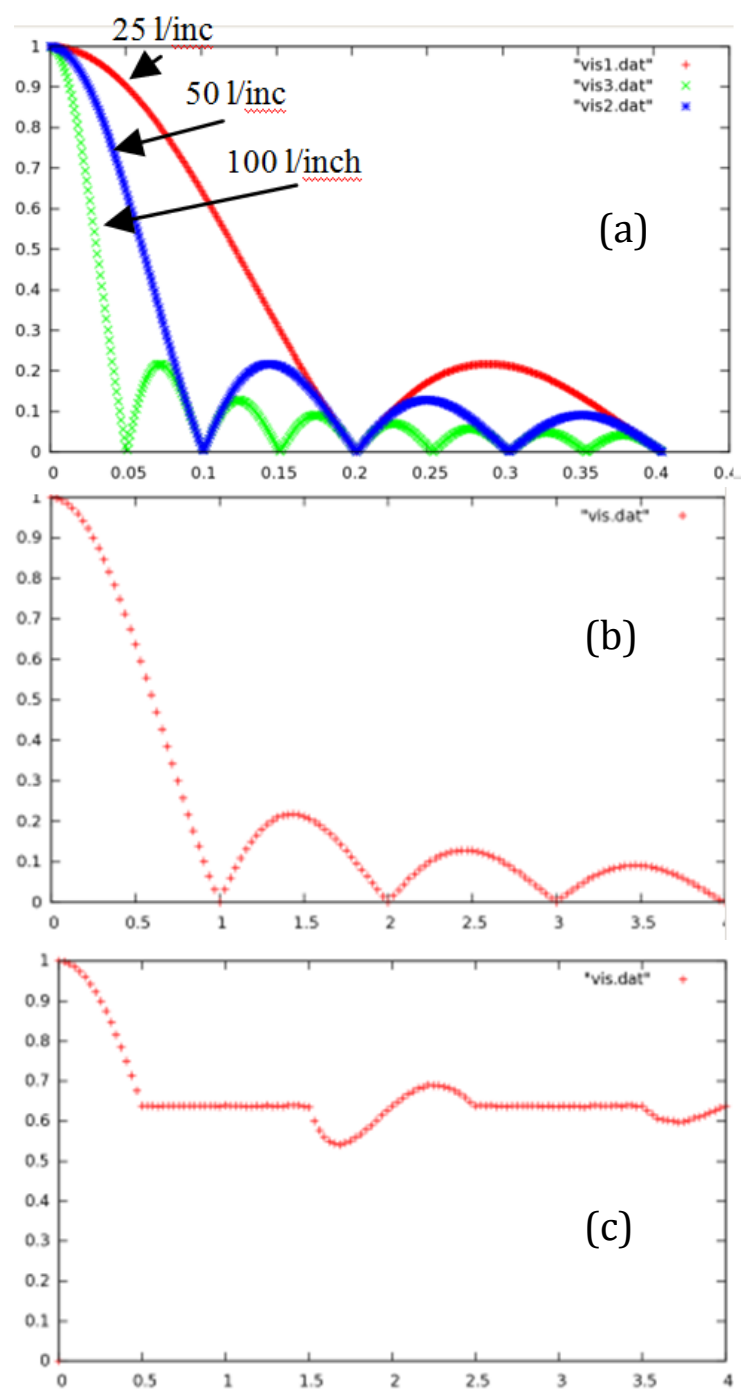

Fig. 4: (a) Graphs of visibility as a function of source size for rulings with 25, 50 and 100 lines per inch. (b) Graph of visibility as a function of source size measured in one ruling period unities. (c) Graph of visibility as a function of source size, case with ruling after the source.

domain $0 \leq c \leq 1$ and $0 \leq L \leq 16 d$, where $d$ is Ronchi ruling period. As we can see in Fig. 5, visibility is equal to 1 if: a) $L=0$ (Line 1 ), this is a point source and b) $c \rightarrow 0$ (line 2) which is equivalent to place point sources at the center of transparent zones of Ronchi ruling. The second case is equivalent to use only one point source, however with several sources maximum intensity is higher. In Fig. 4, line 4 represents the case $c=1$; this means that source is not from behind ruling. Line 3 represents the case $c=1 / 2$; this is the most common case, in which $\checkmark$ falls as $L$ is increased but keeping an acceptable visibility. 


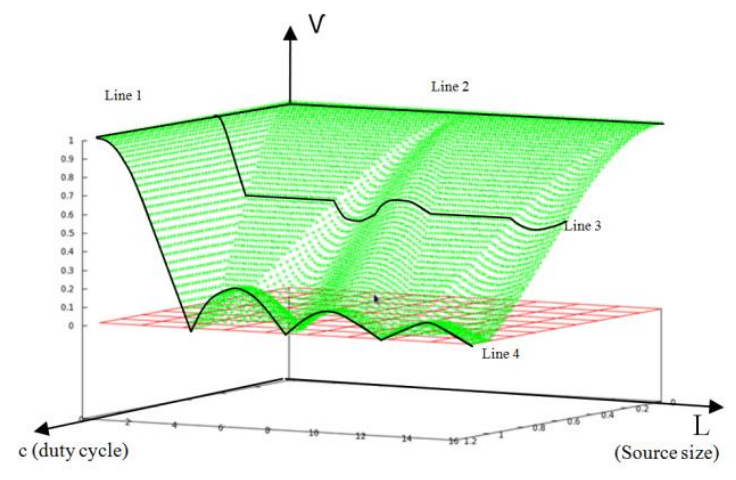

Fig. 5: Graph of visibility vs. linear source size and duty cycle of Ronchi ruling..

\section{Conclusions}

From the point of view of geometrical optics, it can be calculated and analyzed the visibility of any ronchigram for any linear source size and any duty cycle value, reproducing satisfactorily experimental results.

From our results it can be concluded that it is possible to improve notoriously ronchigram visibility if $c$ is correctly chosen. 